\title{
PEMBUATAN PETA GEOSPASIAL MELALUI PEMETAAN UDARA PADA KELURAHAN BATU BERSURAT, KECAMATAN XIII KOTO KAMPAR, KABUPATEN KAMPAR, PROVINSI RIAU
}

\author{
Feblil Huda $^{1^{*} \text {, Kaspul Anuar }}{ }^{1}$, Syafri ${ }^{1}$, Anita Susilawati ${ }^{1}$. \\ ${ }^{1}$ Jurusan Teknik Mesin, Fakultas Teknik, Universitas Riau; Kampus Bina Widya, Jln. HR \\ Subrantas, Pekanbaru \\ *E-mail : feblil.huda@eng.unri.ac.id
}

\begin{abstract}
One of the most commonly used geospatial mapping methods is photogrammetry (aerial mapping). Photogrammetry is a method of mapping objects on the surface of the earth by using aerial photography as a medium. The aerial mapping process is carried out through cameras installed on Unmanned Aerial Vehicle (UAV). From the aerial photography, object interpretation and geometry measurements will be carried out to produce line maps, digital maps and photo maps. In general, photogrammetry is a mapping technology by utilizing aerial photography to be processed into a geo-spatial information system. Batu Bersurat Village is one of the villages located in Subdistrict XIII Koto Kampar, Kampar Regency, which did not have a geospatial information map. Community service team from the Mechanical Engineering Department of the University of Riau had a plan to carry out community service activities in Batu Besurat Village in the form of making geospatial information maps through aerial mapping. This aerial mapping activity was carried out by utilizing UAV with the type of fixed wing. In its implementation, the community service activities were planned to involve Mechanical Engineering students, university students of the University of Riau, village officials and the local community. It is expected that with this community service program, the geospatial information system map made by Batu Bersurat Village can be used in village spatial planning for agricultural land, residential land and validation of village boundaries.
\end{abstract}

Keywords-air, mapping, maps, geospatial

\begin{abstract}
Abstrak
Salah satu metode pemetaan geospasial yang sering digunakan adalah fotogrametri (pemetaan udara). Fotogrametri adalah suatu metode pemetaan objek dipermukaan bumi dengan menggunakan foto udara sebagi media. Proses pemotretan udara dilakukan melalui kamera yang terpasang pada Pesawat Terbang Tanpa Awak (PTTA). Dari foto udara tersebut, akan dilakukan penafsiran objek dan pengukuran geometri untuk selanjutnya dihasilkan peta garis, peta digital maupun peta foto. Secara umum fotogrametri merupakan teknologi pemetaan dengan memanfaatkan photo udara untuk diolah menjadi sistem informasi geo-spasial. Kelurahan Batu Bersurat merupakan salah satu desa yang terletak di Kecamatan XIII Koto Kampar, Kabupaten Kampar, yang belum memiliki peta informasi geospasial. Tim dosen dari Jurusan Teknik Mesin Universitas Riau berencana untuk melakukan kegiatan pengabdian masyarakat di Kelurahan Batu besurat dalam bentuk pembuatan peta informasi geospasial melalui pemetaan udara. Kegiatan pemetaan udara ini akan dilakukan dengan memanfaatkan Pesawat Terbang Tanpa Awak (PTTA) tipe fixed wing, karya Jurusan Teknik Mesin Universitas Riau. Dalam pelaksanaanya, kegiatan pengabdian masyarakat ini direncanakan melibatkan mahasiswa Teknik Mesin, mahasiswa kukerta Universitas Riau, perangkat kelurahan dan masyarakat setempat. Diharapkan dengan adanya program pengabdian kepada masyarakat ini, peta sistem informasi geospasial Kelurahan Batu Bersurat yang dibuat dapat dimanfaatkan dalam perencanaan tata ruang desa baik untuk lahan pertanian, lahan pemukiman maupun validasi batas - batas wilayah desa.
\end{abstract}

Kata Kunci-Udara, Pemetaan, Peta, Geospasial 


\section{PENDAHULUAN}

Peta informasi geospasial sebuah desa/kelurahan disajikan untuk memberikan informasiinformasi berupa batas wilayah, sarana prasarana, bangunan, penggunaan lahan dan jalan [1]. Batas wilayah sebagai salah satu unsur peta desa/kelurahan perlu dipetakkan secara detail dikarenakan hal tersebut kadang menjadi pemicu konflik wilayah di kawasan perdesaan/kelurahan [2]. Pemetaan desa dalam bentuk peta informasi geospasial, dilakukan sebagai bentuk implementasi UndangUndang Nomor 4 Tahun 2011 tentang Informasi geospasial dan Undang Nomor 6 Tahun 2014 tentang Desa. Berdasarkan Undang-Undang Nomor 6 Tahun 2014, didefinisikan bahwa desa adalah kesatuan masyarakat hukum yang memiliki batas wilayah yang berwenang untuk mengatur dan mengurus urusan pemerintahan, kepentingan masyarakat setempat berdasarkan prakarsa masyarakat, hak asal usul, atau hak tradisional yang diakui dan dihormati dalam sistem pemerintahan Negara Kesatuan Republik Indonesia [3]. Batas wilayah Desa yang dinyatakan dalam bentuk Peta Desa ditetapkan dengan peraturan Bupati/Walikota. Undang-Undang tersebut pada Pasal 17 mengamanatkan bahwa Peraturan Daerah Kabupaten/Kota tentang pembentukan, penghapusan, penggabungan, dan perubahan status desa menjadi kelurahan atau kelurahan menjadi desa diundangkan setelah mendapat nomor registrasi dari gubernur dan kode desa dari menteri disertai Lampiran Peta Batas Wilayah Desa [1]. Desa atau kelurahan dipandang sebagai titik awal pemberdayaan potensi daerah, penyelesaian masalah dalam masyarakat, dan komunitas terkecil yang harus diperhatikan kesejahteraannya [4].

Kelurahan Batu Bersurat adalah pindahan dari Daerah Aliran Sungai (DAS) Kampar, dan merupakan Ibu Kecamatan XIII Koto Kampar, Kabupaten Kampar, Provinsi Riau. Kelurahan Batu Bersurat berada di perbukitan dengan jenis tanah kuning berbatu kerikil dan mengandung batu napal. Salah satu kendala dalam perencanaan pembangunan dan tata ruang di Kelurahan Batu Bersurat adalah ketiadaan peta informasi geospasial terkini wilayah kelurahan. Akibatnya tata ruang wilayah desa terkait area pemukiman, area pertanian dan area peruntukan lainya tidak terencana dengan baik. Jika tata ruang desa tidak direncanakan dengan baik, maka kedepan dikhawatirkan area pertanian/perkebunan di wilayah Kelurahan Batu Bersurat akan berkurang akibat semakin berkembangnya wilayah pemukiman. Ketiadaan peta informasi geospasial di Kelurahan Batu Bersurat dan daerah sekitarnya juga berakibat buramnya batas - batas wilayah desa dikarenakan terjadinya pemekaran desa. Hal ini jika tidak diselesaikan, kedepan akan menjadi potensi masalah/konflik.

Berdasarkan pada permasalahan diatas, Pada tahun 2018, tim dosen dari Teknik Mesin Universitas Riau melaksanakan kegiatan pengabdian masyarakat dalam bentuk pembuatan peta informasi geospasial melalui foto udara pada area Kelurahan Batu Bersurat. Kegiatan pemetaan udara di Kelurahan Batu Bersurat dilakukan dengan memanfaatkan Pesawat Terbang Tanpa Awak (PTTA) tipe fixed wing karya Jurusan Teknik Mesin Universitas Riau. Kegiatan pengabdian masyarakat ini, pelaksanaanya melibatkan mahasiswa teknik mesin, mahasiswa kukerta Universitas Riau, perangkat desa dan masyarakat setempat. Diharapkan dengan adanya program pengabdian kepada masyarakat ini, peta sistem informasi geospasial Kelurahan Batu Bersurat yang dibuat, dapat dimanfaatkan dalam perencanaan tata ruang desa baik untuk lahan pertanian, lahan pemukiman maupun validasi batas - batas wilayah desa.

\section{METODE}

Metode yang dilakukan dalam pembuatan peta informasi geospasial pada Kelurahan Batu Bersurat, Kecamatan XIII Koto Kampar, Kabupaten Kampar melalui pemetaan udara dikelompokkan menjadi empat tahap yaitu :

\subsection{Survey awal}

Mengadakan survey awal ke lokasi beserta diskusi/shearing dengan calon kelurahan mitra bertujuan untuk menggali permasalahan terkait tata ruang kelurahan dan peta wilayah kelurahan. Diskusi awal ini juga ditujukan untuk mengkoordinasikan rencana pelaksanaan kegiatan, menggali potensi keterlibatan mitra serta pihak lainya. Kegiatan survey awal ini dilaksanakan dalam rangka 
menysusun proposal pengabdian untuk mendapatkan analisis situasi terhadap khalayak masyarakat (mitra).

\subsection{Persiapan Kegiatan Pengabdian Masyarakat}

Pada tahap ini, tim akan melakukan tahap persiapan peralatan dan bahan yang dibutuhkan dalam pelaksanaan kegiatan pengabdian. Kegiatan diawali dengan mencetak fuselage menggunakan material fiberglass, fiber carbon dan resin epoxy. Berikut ditampilkan gambar 1. Hasil cetakan fuselage

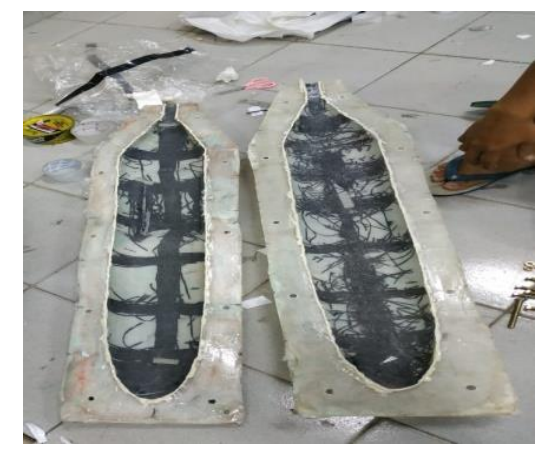

Gambar 1. Hasil cetak fuselage fiberglass

Kedua bagian fuselage tersebut disatukan menggunakan resin epoxy. Terakhir proses finishing fuselage dilakukan menggunakan dempul dan cat agar didapat fuselage yang rapi. Berikut ditampilkan gambar 2 Fuselage yang telah diberikan perlakuan finishing

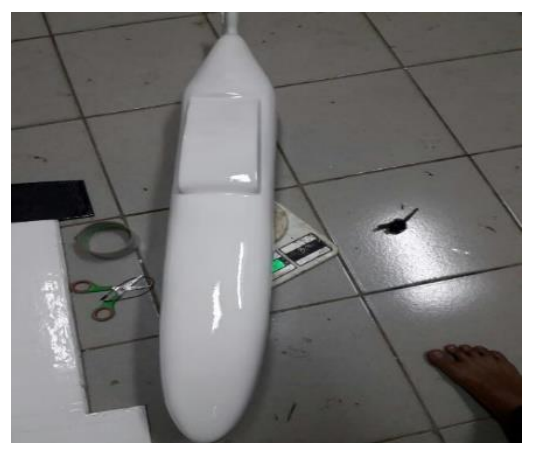

Gambar 2. Fuselage yang telah diberikan perlakuan finishing

Langkah persiapan berikutnya yang dilakukan yaitu membuat sayap dan ekor menggunakan material Styrofoam hard yang diperkuat material aluminium. Prosesnya diawali dengan mencetak mal airfoil pada triplek, selanjutnya mal tersebut menjadi panduan dalam membentuk sayap dan ekor sesuai dengan airfoil yang telah ditentukan. Berikut ditampilkan gambar 3. Sayap yang telah dibentuk

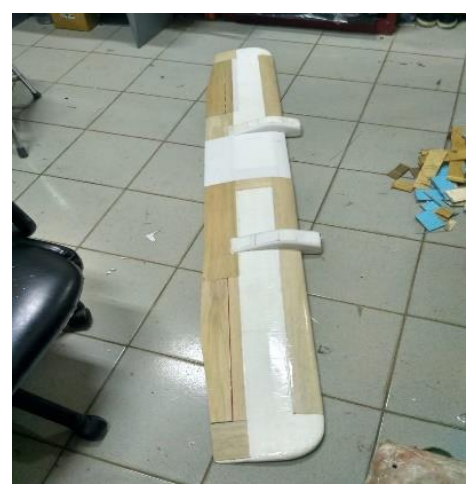

Gambar 3. Sayap yang telah dibentuk 
Setelah fuselage, sayap dan ekor telah berhasil dibuat. Seluruh bagian pesawat terbang tanpa awak tersebut dirakit dan dilakukan pemasangan komponen elektronik. Berikut ditampilkan gambar 4. Perakitan bagian wahana pesawat terbang tanpa awak serta installasi perangkat elektronik

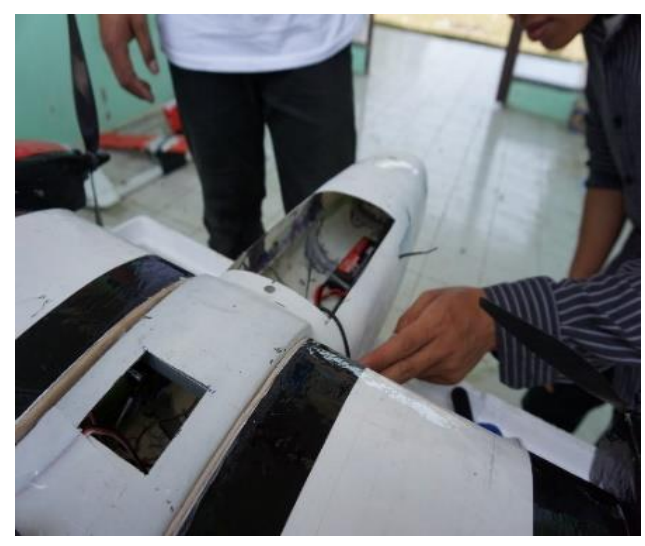

Gambar 4. Perakitan bagian wahana pesawat terbang tanpa awak serta installasi perangkat elektronik

Wahana pesawat terbang tanpa awak yang telah dirakit, kemudian dilakukan uji terbang untuk memastikan wahana dapat berfungsi dan mampu menjalankan misi foto udara dengan baik. proses uji terbang dilakukan di lapangan gedung gasing Universitas Riau. Berikut ditampilkan Gambar 5 proses uji terbang wahana pesawat terbang tanpa awak.

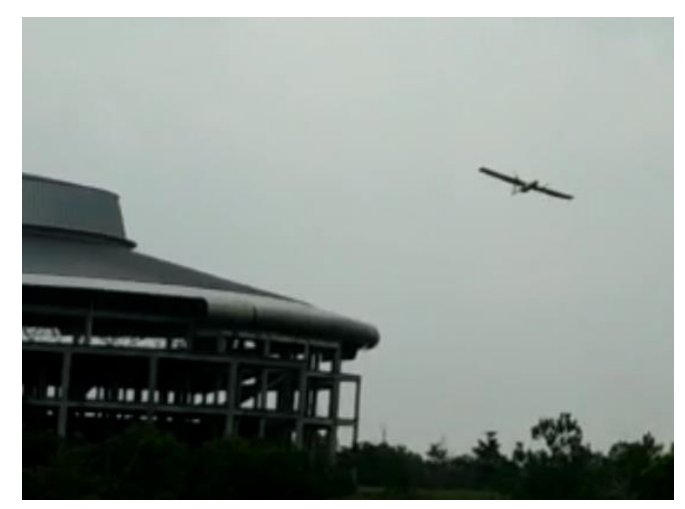

Gambar 5. Proses uji terbang wahana pesawat terbang tanpa awak.

Dari hasil uji terbang, wahana pesawat terbang tanpa awak mampu terbang stabil dan mampu menjalankan misi pemetaan melalui foto udara dengan baik. berikut ditampilkan gambar 6 . Foto udara yang didapat melalui uji terbang wahana pesawat tebang tanpa awak

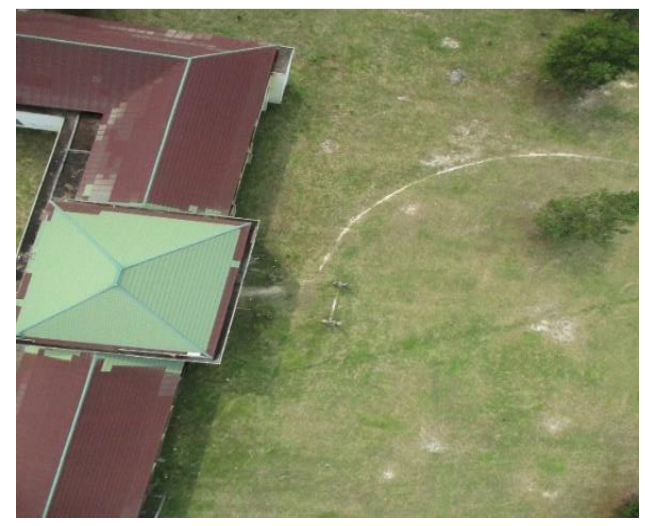

Gambar 6. Foto udara yang didapat melalui uji terbang wahana pesawat tebang tanpa awak 


\subsection{Persiapan Perlengkapan Pendukung Kegiatan Pengabdian}

Pada tahap ini, tim akan melakukan tahap persiapan peralatan, penentuan area of interest (AoI), perencanaan instalasi Ground Control Point (GCP) dan perencanaan jalur terbang. Beberapa peralatan pendukung yang dipersiapkan dalam kegiatan pengabdian ini yaitu spanduk penunjuk titik ground control point. Spanduk GCP ini dicetak sebanyak 10 buah agar akurasi 3D peta udara yang dihasilkan dapat maksimal.

Untuk perencanaan jalur terbang, lapangan sepak bola yang terdapat di Kelurahan Batu Bersurat dijadikan sebagai area wahana untuk lepas landas (take off) dan landing. Area ini dipilih karena memiliki kondisi clear view yang memadai. Selain itu, di lapangan ini juga terdapat fasilitas colokan listrik, sehingga memudahkan tim pengabdian untuk melakukan pengecasan batere pesawat terbang tanpa awak.

\subsection{Pelaksanaan}

\section{a. Pengambilan Data Foto Udara}

Proses pengambilan data melalui pemetaan udara dilakukan oleh empat orang operator yang masing - masing bertugas sebagai pilot, operator ground control, operator tracking dan operator pengolah data foto pemetaan. Pilot bertugas untuk menerbangkan pesawat hingga ketinggian tertentu sebelum dialihkan ke mode auto. Setelah semua daerah yang difoto selesai, pilot bertugas untuk mendaratkan pesawat. Operator ground control bertugas untuk merencanakan dan membuat jalur terbang pada software mission planner, selain itu juga bertugas untuk memantau kecepatan PTTA, tinggi terbang PTTA melalui komputer. Sedangkan operator tracking bertugas untuk memantau secara langsung attitude terbang dari PTTA selama melaksanakan misi pemetaan udara.

pengambilan data foto udara melalui pesawat terbang tanpa awak tipe fixed wing, dilakukan sebanyak dua kali sortase terbang. Ketinggian terbang wahana pesawat terbang tanpa awak diatur sebesar 250 meter diatas permukaan tanah. Berikut ditampilkan gambar 7 proses persiapan take off wahana pesawat terbang tanpa awak (PTTA) dilokasi pengabdian.

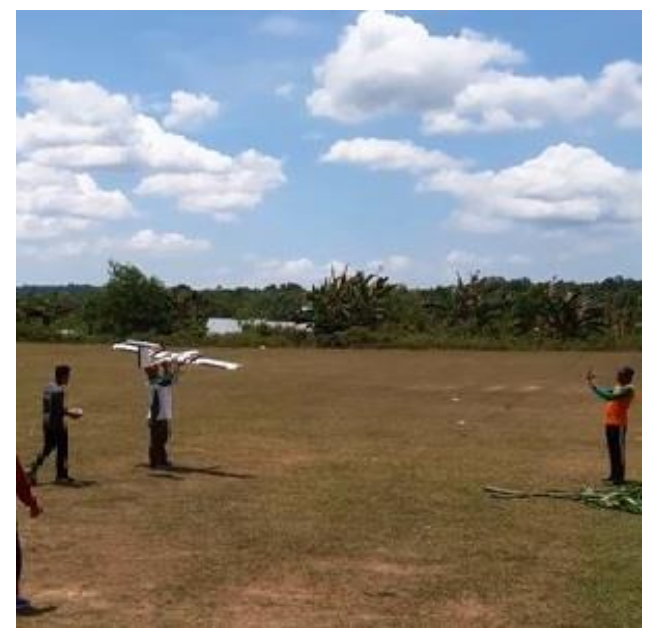

Gambar 7. Proses persiapan Take off wahana PTTA dilokasi pengabdian

Pengambilan data foto udara dilakukan pada siang hari dan pada kondisi langit yang cerah. Hal ini bertujuan agar kamera foto udara yang digunakan dapat bekerja dengan maksimal. Penerbangan pesawat terbang tanpa awak tipe fixed wing dalam rangka pengambilan data foto udara, dilakukan sebanyak dua kali sortase terbang. Ketinggian terbang wahana pesawat terbang tanpa awak diatur sebesar 250 meter diatas permukaan tanah. Berikut ditampilkan gambar 8 pengambilan data foto udara yang dilakukan 


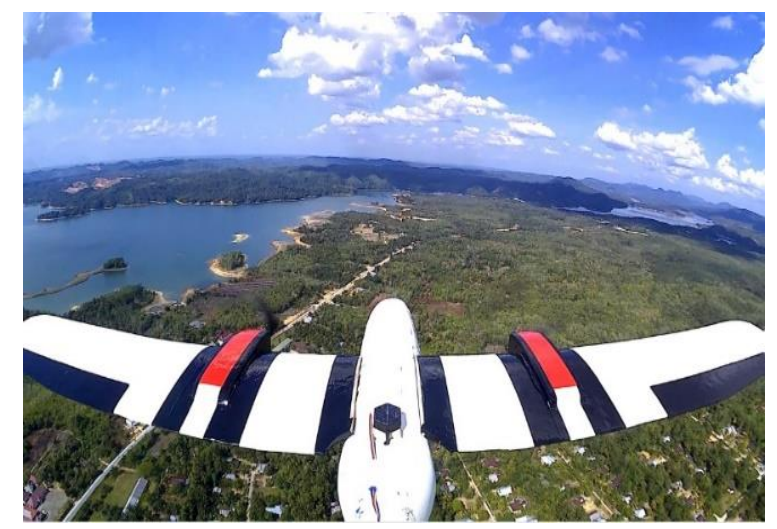

Gambar 8. Pengambilan data foto udara yang dilakukan

\section{b. Proses Pengolahan Foto Udara (Tahap Pasca Lapangan)}

Data foto udara yang telah didapat, selanjutnya dilakukan proses tahap pascalapangan. Tahap ini diawali dengan proses injeksi koordinat GPS kedalam semua data foto udara. Selanjutnya dilakukan proses align photo sampai dengan proses mosaic photo pada software agisoft photo scan. Output dari proses ini yaitu data foto udara yang telah berbentuk peta pada format TIFF. Selanjutnya dilakukan proses layout peta foto udara pada software arcMap. Output dari proses ini yaitu sebuah peta foto udara dengan resolusi tinggi yang telah dilengkapi dengan keterangan baik berupa arah, skala, maupun keterangan metadata. Berikut ditampilkan gambar 9 proses pengolahan foto udara pada software agisoft photo scan

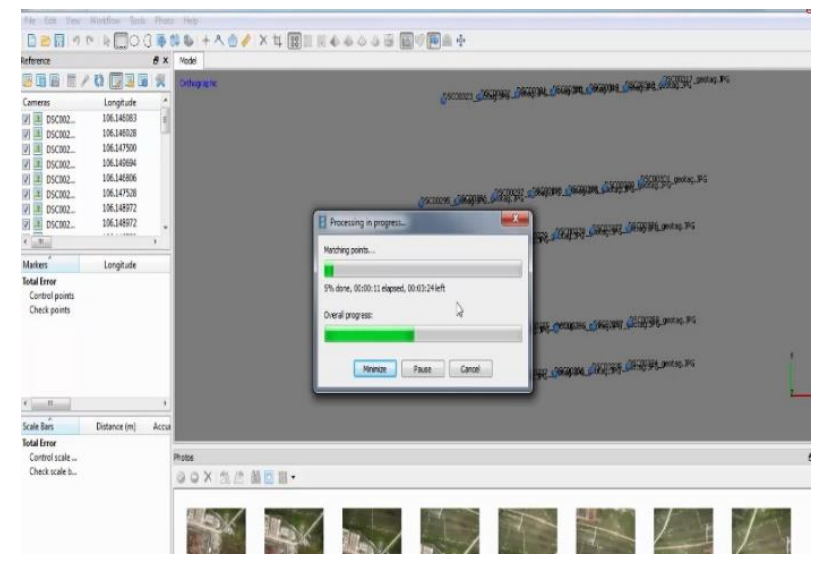

Gambar 9. Proses pengolahan foto udara pada software agisoft photo scan

\section{c. Penyerahan Data Foto Udara Kepada Kelurahan Mitra}

Pengolahan data foto udara Kelurahan Batu Bersurat, Kecamatan XIII Koto Kampar, pada software agisoft photoscan menghasilkan peta foto udara citra resolusi tinggi dalam format JPEG dan Kml. Data peta foto udara dalam format JPEG kemudian dicetak pada banner dengan ukuran 2 meter x 1,4 meter. Data peta foto udara dalam format $\mathrm{Kml}$ dimanfaatkan untuk mengoverlay peta foto udara Kelurahan Batu Bersurat pada software google earth. Soft file dari kedua data peta foto udara ini juga dicopy ke dalam flashdisk, sehingga penyerahan data foto udara kepada kelurahan mitra diberikan dalam bentuk hardcopy dan softcopy.

\section{HASIL DAN PEMBAHASAN}

\subsection{Gambaran umum masyarakat Sasaran}

Seperti yang telah dijelaskan sebelumnya, salah satu kendala dalam perencanaan pembangunan dan tata ruang di Kelurahan Batu Bersurat adalah ketiadaan peta informasi geospasial, dalam bentuk foto udara terkini di wilayah kelurahan. Akibatnya tata ruang wilayah desa terkait area pemukiman, area pertanian dan area peruntukan lainya tidak terencana dengan baik. Jika tata ruang desa tidak direncanakan dengan baik, maka kedepan dikhawatirkan area pertanian/perkebunan di 
wilayah Kelurahan Batu Bersurat akan berkurang akibat semakin berkembangnya wilayah pemukiman. Ketiadaan peta informasi geospasial di Kelurahan Batu Bersurat dan daerah sekitarnya juga berakibat buramnya batas - batas wilayah desa dikarenakan terjadinya pemekaran desa. Hal ini jika tidak diselesaikan, kedepan akan menjadi potensi masalah/konflik.

\subsection{Tingkat Ketercapaian Sasaran Program}

Kegiatan pengabdian masyarakat dalam bentuk pembuatan peta informasi geospasial melalui foto udara pada area Kelurahan Batu Bersurat dilakukan menggunakan wahana pesawat terbang tanpa awak tipe fixed wing. Wahana ini menjalankan misi foto udara di wilayah Kelurahan Batu Bersurat pada ketinggian 250 meter dari atas permukaan tanah. Jumlah foto udara yang dihasilkan dari kegiatan ini sebanyak 216 buah foto dengan proses pengambilanya dilakukan sebanyak dua kali sortase terbang wahana fixed wing. Kegiatan pengabdian masyarakat ini berhasil menghasilkan peta foto udara resolusi tinggi dengan tingkat GSD sampai dengan $5 \mathrm{~cm}$. Hal ini menunjukan bahwa kegiatan pengabdian kepada masyarakat yang telah dilaksanakan oleh tim pengabdian berhasil mencapai tujuan yang telah direncanakan. Peta sistem informasi geospasial dengan citra resolusi tinggi pada Kelurahan Batu Bersurat yang dibuat, dapat dimanfaatkan dalam perencanaan tata ruang wilayah kelurahan baik untuk lahan pertanian, lahan pemukiman maupun validasi batas - batas wilayah dengan desa sekitarnya. Peta sistem informasi geospasial dengan citra resolusi tinggi ini dicetak pada banner dengan ukuran panjang dan lebar masing - masing sebesar 2 meter dan 1,4 meter. Berikut ditampilkan gambar 10 peta informasi geospasial dengan citra resolusi tinggi pada Kelurahan Batu Bersurat, Kecamatan XIII Koto Kampar, Kabupaten Kampar.

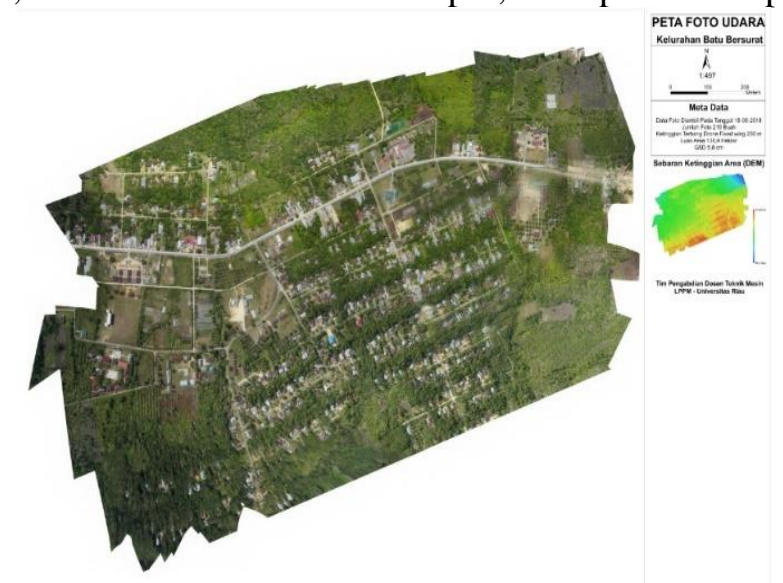

Gambar 10. Peta informasi geospasial resolusi tinggi pada Kelurahan Batu Bersurat

Dengan tingkat resolusi yang tinggi, memungkinkan peta informasi geospasial ini diperbesar dengan detail yang jelas dan akurat. Berikut ditampilkan gambar 11 hasil perbesaran peta informasi geospasial dengan citra resolusi tinggi.

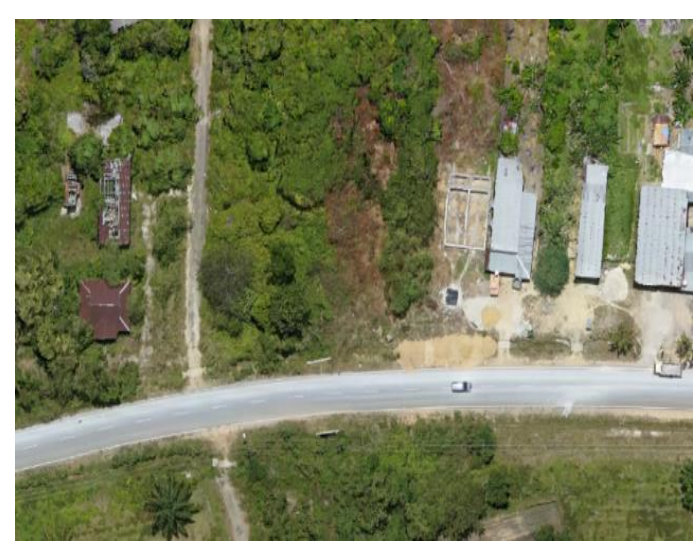

Gambar 11. Hasil perbesaran peta informasi geospasial resolusi tinggi 


\section{KESIMPULAN}

Melalui kegiatan pengabdian kepada masyarakat ini, didapat beberapa luaran dan manfaat yang didapat oleh mitra, diantaranya:

1) Mitra memiliki peta geospasial dengan resolusi tinggi pada Kelurahan Batu Bersurat.

2) Mitra memahami kegunaan dan fungsi dari peta geospasial dalam mendukung upaya perencanaan tata ruang dan kondisi penggunaan lahan terkini di Kelurahan Batu Bersurat.

3) Mitra mengetahui cara mengupdate peta resolusi tinggi kelurahaan batu bersurat pada aplikasi google earth.

\section{SARAN}

Peta geospasial dalam bentuk foto udara yang dihasilkan oleh tim pengabdian hendaknya dapat dikembangkan oleh perangkat kelurahan terkait informasi geosapsial kependudukan lainya, sesuai dengan kebutuhan kelurahan. Sesuai dengan petunjuk yang diberikan tim pengabdian, proses editing peta geospasial dapat dilakukan dengan mudah oleh perangkat kelurahan.

\section{UCAPAN TERIMAKASIH}

Kami menyadari bahwa dalam kegiatan pengabdian ini telah banyak pihak yang membantu. Oleh karena itu kami mengucapkan terima kasih kepada:

1. Bapak Prof. Dr. Almasdi Syahza, SE., MP selaku Ketua Lembaga Penelitian dan Pengabdian Kepada Masyarakat Universitas Riau

2. Dekan Fakultas Teknik Universitas Riau

3. Ketua Jurusan Teknik Mesin Universitas Riau

4. Rekan - rekan dosen Jurusan Teknik Mesin Universitas Riau

\section{DAFTAR PUSTAKA}

[1] Muryamto, Rochmad. 2016. "Pembuatan Peta Dan Sistem Informasi Geospasial Lahan Pertanian Di Kecamatan Sentolo, Kabupaten Kulonprogo, Yogyakarta.

[2] Hidayat, (2005), Seri Panduan Pemetaan Partisipatif No. 2 - Mengenalkan Pemetaan Partisipatif,Garis Pergerakan, Bandung.

[3] RI (Republik Indonesia). (2014). Undang-Undang No. 6 Tahun 2014 tentang Desa. Lembaran Negara RI Tahun 2014, No.7. Hukum dan Hak Asasi Manusia. Jakarta.

[4] Muhi, Ali. (2011). Pemetaan dan Penentuan Potensi Desa. Alqaprint. Jatinangor 